on Ocean Affairs that represents a broad spectrum of oceanographic institutions. One day will be devoted to Society business. one day to the Congressional Forum, and one day to the affairs of the Council on Ocean Affairs. Ed Frieman. Director of Scripps Institution of Oceanography, has agreed to chair the Program Committee for this meeting.

We also plan to establish a series of awards and recognition for scientific achievement, not limited to but with a special emphasis on young scientists and students. Early recognition of outstanding work is an important feedback to a young person who wants to develop a career, and the Society can provide such recognition. We hope to develop a full range of awards for recognition of achievement.

The Society has been funded to provide support for educational activities by NSF, NASA and Office of Naval Research (ONR). Both NSF and NASA have provided funds for support of the next meeting of academic deans of oceanography that will take place this fall. ONR has provided support for the publishing of a booklet showing career opportunities for disabled persons in oceanography. We hope to make this the beginning of a series of career booklets. At the Inalugural Meeting. Sue Weiler chaired a meeting on the issues faced by dual-career couples. This could also be a topic that the Society helps develop. We hope to broaden the membership to make it as international as possible. At the
Inaugural meeting, eight countries outside the US were represented: Australia, Brasil. Canada, France, Germany. Korea, Mexico, Norway and Portugal. The support of the Society by international groups such as SCOR and International Association for the Physical Scicnces of the Ocean is welcomed, and we hope that it can be mutually beneficial. Charlie Miller has agreed to be Chairman of our Membership Committee and will be contacting the membership for suggestions.

We are planning a major mailing of Society information to oceanographers outside the US in order to broaden our membership as much as possible. The field of oceanography is international, and the Society should reflect this. We also are looking to ways to affiliate and work with national societies related to ocean science. particularly in exchange of publications like Oceanography Magazine.

For me. the meeting was the inspirational point of a recent round of experiences that might be worth recounting. In July, I attended the biennial Assembly of the Intergovermmental Oceanographic Commission (IOC) in Paris. There was a strong sense of renewed commitment to the IOC from its member countries because of the world-wide recognition of the need for documenting. understanding and predicting global change. The new opportunities offered by this recognition could help to put in place the programs that we have all been working for.
Early in August. I gave a series of lectures in Brazil for the United States Information Agency. I was struck by the growing interest. desire and enthusiasm for a strong ocean program in that country: in spite of its economic and social problems. Brazil has a vital science enterprise that could have a major impact on all aspects of life. There was a strong interest there in developing joint programs with The Oceanography Society. Then, at the end of August. I came to Monterey, where themes of ocean science were interspersed with advice and wisdom from the long-time leaders of the field.

I found this total experience inspiring and exciting. and it seems to me to sum up our challenges and opportunities in ocean science today: an understanding of the environment is more important than ever: the necessary technology is mostly available and ready to be used: and there is a complete cast of characters-the occanographic community-ready to make things happen.

As your president, I am prepared to work with you and to make things happen. In September, the Council had its first meeting, and we set a course of action for the future. As we go, we will look to you. the members. for advice and support. Please help: as I urged at the meeting. enroll your colleagues in the Society. We re looking forward to working with a broad community in the Society for the ocean sciences. ב

\title{
Measurement of Photosynthetic Response to Euphotic Zone Physical Forcing
}

\author{
By Gary J. Kirkpatrick, Thomas B. Curtin, Daniel Kamykowski, and Michael Feezor
}

\begin{abstract}
$\mathrm{W}_{\mathrm{E}}$ innovative biophysical in situ measurement system to investigate the role of vertical motion in the photosynthetic response of
\end{abstract}

Gary J. Kirkpatrick and Ditniel Kamykowsk, Bor 8208, Marine. Earth and Amospheric Science, North Carolina State Liniversity. Raleigh. NC 27695-8208; Thomas B. Curtin. Office of Naval Rescarch. Code 1125AR. 800 N. Quincy. Arlington. VA 22217: Michael Feezor, Electronic Design Consultants, Inc.. P.O. Box 2008. Chapel Hill, NC 27514.

Editor's Note:

This is the abstract of the winning student poster at TOS's Inaugural Meeting phytoplankton within the upper mixing layer of the ocean. The two elements of the system are highly alutomated ensembles of sensors and control mechanisms integrated to obtain coincident measurements of photosynthesis and velocity/density. The scales of physical motion addressed locally range from one centimeter to one meter and ten hertz to ten days. To cover larger spatial scales such systems can be nested in arrays. Velocity is sensed electromagnetically with electrodes distributed to resolve a wave number/frequency spectral window thought to be important in defining plankton trajec- tories. The self-contained, in situ photosynthesis device acquires multiple rate estimates from a contained culture. Photosynthetic response is obtained on time scales from approximately five minutes to twentyfour hours by controlling the range of $\mathrm{pH}$ and dissolved oxygen within the culture. A principal objective of the measurement is to determine the coherence between physical forcing and phytoplankton response. Recent prototype field data are presented to demonstrate performance and compare output from this system with standard techniques of photosynthesis measurement. $\square$ 